\title{
Parasitic Diseases of Domestic and Wild Animals in Northern Kerala: A Retrospective Study based on Clinical Samples
}

\author{
Murikoli Nimisha, R. Kariyappa Pradeep, Prashant S. Kurbet, \\ B.M. Amrutha, Anju Varghese, C.K. Deepa, M.N. Priya, \\ Bindu Lakshmanan, K.G. Ajith Kumar and Reghu Ravindran*
}

\author{
Department of Veterinary Parasitology, College of Veterinary and Animal Sciences, \\ Pookode, Lakkidi P.O., Wayanad-673576, Kerala, India \\ *Corresponding author
}

\begin{tabular}{|c|c|}
\hline \multicolumn{2}{|r|}{ A B S T R A C T } \\
\hline & \multirow{6}{*}{$\begin{array}{l}\text { Results of microscopical examination of clinical samples from domestic and wild animals } \\
\text { for an } 11 \text { year period from } 2005 \text { to } 2015 \text { submitted to the Department of Veterinary } \\
\text { Parasitology, College of Veterinary and Animal Sciences, Pookode were compiled in the } \\
\text { present study to understand the prevalence of parasitic diseases in Northern Kerala, South } \\
\text { India. Majority of samples were collected from animals belonging to the districts of } \\
\text { Northern Kerala viz., Kasaragod, Kannur, Wayanad, Kozhikode and Palakkad. A total of } \\
2,473 \text { fecal samples, } 2,183 \text { peripheral blood smears, } 92 \text { skin scrapings and } 12 \text { nasal } \\
\text { discharges of cattle, goat, dog, poultry, pig, buffalo, horse, cat and wild animals were } \\
\text { examined. Strongylosis was the predominant cause of gastrointestinal parasitosis in cattle } \\
\text { and goats with the prevalence rates of } 11.35 \text { per cent and } 36.63 \text { per cent respectively. } \\
\text { Ancylostomosis with a prevalence rate of } 18.23 \text { per cent was the predominant helminthic } \\
\text { infection in dogs. Major blood parasite detected in cattle was Theileria orientalis. Babesia } \\
\text { gibsoni was the main blood parasite of dogs. Maximum numbers of cases on } \\
\text { gastrointestinal parasitism were reported during September in ruminants (cattle and goats) } \\
\text { and July in dogs. Maximum numbers of cases of haemoparasitic diseases were reported in } \\
\text { January in cattle and November in dogs. Microscopical examination of skin scrapings from } \\
\text { dogs revealed maximum prevalence of Demodex canis in Northern Kerala. }\end{array}$} \\
\hline & \\
\hline & \\
\hline Article Info & \\
\hline $\begin{array}{l}\text { Accepted: } \\
17 \text { September } 20 \\
\text { Available Onlin } \\
10 \text { November } 20\end{array}$ & \\
\hline & \\
\hline
\end{tabular}

\section{Introduction}

Parasitic diseases are one of the major constraints for livestock rearing in developing countries. According to the $19^{\text {th }}$ livestock census (2012), the livestock population in India is 512.05 million, which includes the rural population of 491.69 million and urban population of 31.31 million. Parasitic diseases contribute 31 per cent of livestock diseases and were more among cattle (13.83 per cent) followed by poultry (9.71 per cent) and goats
(5.62 per cent) (ADSS, 2007). Most of the rural livestock population is reared on grazing based system and these animals are always exposed to parasites, thus constantly being reinfected in a chain reaction mode (Kumar et $a l ., 2013)$. The annual growth rate of Indian cattle population is only 0.5 per cent against the expected rate of 1.0 per cent of total livestock population mainly caused by helminthic infections (Swapna and Nithinya, 
2015). Certain endoparasitic infections and ectoparasitic infestations of canines and felines have public health significance due to their zoonotic potential. Also, parasitic diseases of wild animals cause serious problems and they can act as sources of infections to domestic animals. Haemoprotozoan diseases transmitted by ticks cause serious economic losses in Asia and have become a potential barrier for the survival of exotic and crossbred cattle in India (Velusamy et al., 2014).

In order to assess the prevalence of parasitic diseases in animals in Northern Kerala, a retrospective study based on the data available from the register maintained for recording the results of microscopical examination of clinical samples submitted to the Department of Veterinary Parasitology, College of Veterinary and Animal Sciences, Pookode, Wayanad was conducted during a period from 2005 to 2015 (11 years). The results of the present study on the prevalence of parasitic diseases in Northern Kerala will be helpful for veterinarians and farmers for adopting effective control measures.

\section{Materials and Methods}

This study was conducted by analyzing the data available from the register maintained for recording the results of microscopical examination of clinical samples from cattle, goat, dog, buffalo, poultry, pig, horse and wild animals submitted to the Department of Veterinary Parasitology, College of Veterinary and Animal sciences, Pookode, Wayanad during 2005 to 2015.

Majority of clinical samples were collected from animals belonging to the districts of Northern Kerala viz., Kasaragod, Kannur, Wayanad, Kozhikode and Palakkad. Details of the clinical samples examined are shown in table 1 and 2.

\section{Fecal sample}

A total of 2,473 fecal samples were examined from cattle $(n=1,304)$, goat $(n=505)$, dog $(n=192)$, poultry $(n=175)$, pig $(n=57)$, buffalo $(n=49)$, horse $(n=42)$, cat $(n=17)$ and wild animals $(n=132)$. All the samples were screened for the ova of helminths and oocysts of coccidian parasites. Fecal samples were processed for concentration of ova by centrifugal sedimentation method and were microscopically examined under 10X objective, followed by $40 \mathrm{X}$ for confirmation.

\section{Blood smears}

A total of 2,183 peripheral blood smears were examined from various animals and birds viz., cattle $(n=1,217)$, goat $(n=321)$, buffalo $(n=35), \operatorname{dog}(n=509)$, pig $(n=20)$, horse $(n=8)$, cat $(n=3)$, wild animals $(n=24)$ and poultry $(n=46)$. Thin blood smears were fixed with methanol for 2 minutes and stained with diluted Giemsa's stain (1:10) for 45 minutes. Blood smears were carefully examined for the presence of blood parasites under the oil immersion objective (100X magnification).

\section{Skin scrapings}

Superficial and deep skin scrapings from cattle $(n=17), \operatorname{dogs}(n=51)$, goats $(n=13)$, pigs $(n=8)$, cats $(n=2)$ and buffalo $(n=1)$ were screened for ectoparasites. The scrapings were digested in 10 per cent potassium hydroxide solution and centrifuged. The sediment was examined under 10X and 40X objectives of the microscope.

\section{Nasal discharge}

A total of 12 nasal discharges from cattle were examined for Schistosoma nasale infection. Potassium hydroxide solution (10 $\%)$ was added to the nasal discharge in a test tube. The mixture was boiled to lyse any 
mucus content in the sample. Finally, centrifuged at $3000 \mathrm{rpm}$ for $3 \mathrm{~min}$ and sediment was examined under microscope.

\section{Results and Discussion}

A retrospective study was conducted to analyze the records of results of microscopical examination of clinical samples submitted to the Department of Veterinary Parasitology, College of Veterinary and Animal Sciences, Pookode, Wayanad from 2005 to 2015 to find out the prevalence of parasitic diseases in Northern Kerala. Out of the 2,473 fecal samples examined, 1,101 $(44.52 \%)$ were positive for ova of gastrointestinal parasites. Of the 2,183 blood smears that were screened, $684(31.33 \%)$ were positive for blood parasites. On examination of 92 skin scrapings, 20 $(21.74 \%)$ were positive for mite infestation. The results of the screening of clinical samples are shown in table 1 and 2.

\section{Cattle}

The copro-examination of cattle from 2005 to 2015 accounted, 455 (34.89\%) positive cases out of 1,304 samples. Of this overall prevalence, 50.99 per cent was due to the ova of nematodes, 28.79 per cent for the trematodes, 18.68 per cent for oocysts of protozoan parasites and 1.53 per cent for ova of the cestode (Moniezia spp.).

Parasitological examination of dung samples revealed the presence of ova of strongyle, Strongyloides spp., Trichuris spp., Toxocara spp., amphistome, Schistosoma spindale, Moniezia spp. and oocysts of coccidia. In the present study, highest prevalence was recorded for strongylosis $(11.35 \%)$ followed by amphistomosis (9.36\%) and coccidiosis $(6.13 \%)$. Month wise study revealed highest incidence of infection during the month of September (47.79\%) followed by August
(46.03\%) and least during April (26.51\%). On microscopic examination of the Giemsa's stained peripheral blood smears $(n=1217)$ of cattle, $527(43.30 \%)$ were positive for haemoprotozoan organisms. Babesia spp., Theileria spp. and Anaplasma spp. were identified in these samples. Theileria orientalis was the most predominant blood parasite of cattle accounting 32.62 per cent of the total positive cases. The incidence of haemoparasitic diseases were reported more during the month of January $(62.77 \%)$ and November (58.17\%). During 2007, a survey for detection of oocysts of Cryptosporidium spp. was conducted using 44 bovine fecal samples and five were identified as positive. Out of 17 skin scrapings examined, none were detected as positive for any ectoparasitic infestations. The examination of nasal discharge detected three samples positive for S. nasale out of 12 samples.

\section{Goat}

A total of 505 goat fecal samples were examined. The overall prevalence of intestinal parasitosis was 71.68 per cent. The prevalence of strongylosis $(36.63 \%)$ was the highest, followed by coccidiosis (14.65\%). Ova of Moniezia spp. (7.33\%), Strongyloides spp. (6.34\%), Trichuris spp. (5.35\%) and amphistomes (1.39\%) were also detected.

The month wise prevalence of intestinal parasitosis was highest in September (93.18\%) and lowest in February (30.23\%). Among 321 caprine blood smears examined, $78(24.29 \%)$ were positive for Theileria spp. (13.08\%) and Anaplasma spp. (11.21\%). The percentage prevalence of caprine anaplasmosis increased steadily during the period from 2005 to 2015 . In goats, parasitism was more during the month of September (50\%) and least during July (12.55\%). Only 13 skin scrapings were examined and Psoroptes ovis was detected in three cases. 


\section{Buffalo}

A total of 49 buffalo fecal samples were examined for the detection of ova of various intestinal parasites. Nineteen samples were positive, representing an overall prevalence of 38.78 per cent. Strongyle $(16.33 \%)$ ova were the predominant ova observed. Oocysts of coccidia (10.2\%) and ova of Strongyloides spp. (8.16\%), Toxocara spp. (2.04\%) and amphistomes $(2.04 \%)$ were also detected. On examination of 35 blood smears of buffalo, 17.14 per cent were positive for Theileria spp. and 2.86 per cent for Anaplasma spp.

\section{Dog}

Examination of fecal samples of dogs for gastrointestinal parasites $(n=192)$, revealed 81 samples (42.19\%) as positive. Ova of Ancylostoma spp. (18.23\%) was the most prevalent parasitic ova identified during the 11 years period, followed by ova of Taenia spp. (13.54\%) and Toxocara canis (7.29\%). Other than this, ova of Spirocerca lupi and oocyst of Isospora spp. were also detected. Month wise data indicated that maximum number of positive cases were recorded during the month of July $(66.67 \%)$ and least during April. Out of 509 blood smears examined, $46(9.04 \%)$ were positive for blood parasites. The blood parasites of dogs identified were B. gibsoni (4.72\%), Ehrlichia spp. (1.18\%), Hepatozoon spp. (0.2\%), Trypanosoma evansi $(0.2 \%)$ and microfilaria $(2.75 \%)$ of Dirofilaria repens. The study revealed a steady increase in the occurrence of $B$. gibsoni cases from 2005 to 2015 . The lowest incidence of blood parasite infection was recorded in the month of June (2.94\%) and highest during November (15.63\%). On examination of 51 skin scrapings, 12 were positive for mite infestations. Demodex canis was the major mite species detected in skin of dogs with a prevalence of 21.57 per cent. Sarcoptes spp. was also identified with a low prevalence of 1.96 per cent.

\section{Cats}

Coprological examination of cat samples revealed ova of Toxocara spp. (29.41\%) as the most predominant one. Other parasitic eggs identified were ova of strongyle (5.88\%), Capillaria spp. (5.88\%) and oocysts of Isospora spp. (5.88\%).

\section{Pigs}

From the 57 porcine fecal samples examined, only coccidia oocysts $(5.26 \%)$ and strongyle ova $(1.75 \%)$ were detected. No samples of pigs were submitted after 2012. No blood parasites could be detected in pigs. Examination of 8 skin scrapings revealed Sarcoptes scabei infestations in five pigs.

\section{Horses}

Strongyle ova $(30.95 \%)$ was the only ova of gastrointestinal parasites detected during the examination of fecal samples of horses $(n=42)$. The blood smear examination of the horses revealed no parasites.

\section{Poultry}

A retrospective analysis of the 175 fecal samples of poultry identified 26.86 per cent of intestinal parasitosis. Coccidial (13.71\%) infection was the predominant parasitism. Other ova of parasites encountered were Ascaridia spp. (5.14\%), strongyle (3.43\%), Capillaria spp. (3.43\%), Syngamus trachea $(0.57 \%)$ and Railleitina spp. (0.57\%). Among 46 blood smears of pigeons examined, 22 were positive for Haemoproteus columbae representing an overall prevalence of 47.83 per cent.

\section{Wild Animals}

On examination of 70 fecal samples of tiger, ova of Spirometra spp. (44.29\%) and Paragonimus spp. (34.29\%) were 
predominant. Ova of Taenia spp. (8.57\%), strongyle (7.14\%), Toxocara spp. (4\%), Strongyloides spp. (3\%) and Trichuris spp. (1\%) were also identified. Trypanosoma evansi was the only blood parasite of tiger detected during examination of five blood samples. Only one fecal sample of leopard was examined and was positive for Strongyloides spp. Ova of strongyle (33.33\%) and Toxocara spp. (33.33\%) were detected from python feces $(n=6)$.

Blood smear examination of python detected haemogregarine organisms in one sample. Fecal samples $(n=11)$ of elephants were positive for strongyle $(\mathrm{n}=1)$ and cysts of Balantidium coli like $(\mathrm{n}=1)$. From 20 fecal samples of lion examined, 13 were positive for Toxascaris spp. followed by Toxocara spp. (30\%), Strongyloides spp. (10\%), Isospora spp. (5\%) and Schistosoma spindale $(5 \%)$. Strongyles were the predominant gastrointestinal parasite of monkeys.

Ova of Taenia spp. and Strongyloides spp. were also identified in the fecal samples of monkeys. Deer fecal samples revealed single positive case of both Moniezia spp. and Strongyloides spp. from a total of eight samples. Out of six blood smears of deers examined Theileria spp. and Babesia spp. were identified in one sample each.

Parasitism, mainly endoparasitism produces various ill effects like emaciation, weakness, inappetance and predisposes to various other potential pathogens (Allwin et al., 2016). The rate of morbidity and mortality due to bacteria and viruses are reducing and losses due to parasites are increasing, thus it is high time to give more emphasis on systematic control of parasitic diseases (Vanisri et al., 2016).

This retrospective study analyzed the data available in the register maintained at Department of Veterinary Parasitology,
College of Veterinary and Animal Sciences, Pookode from January 2005 to December 2015 for microscopical examination of clinical samples. Based on the analyses, it can be inferred that cattle were mainly infected by nematodes, followed by trematodes. The occurrence of cestode infections among cattle was relatively low.

Similar findings were observed by Vanisri et al., (2016) who conducted a study on intestinal parasitosis of nondescript cattle of Tamil Nadu. However, Swapna and Nithinya (2015) reported trematodes as the major parasites of gastrointestinal tract of slaughtered cattle from Kannur, a district in northern Kerala.

Strongyles were the predominant gastrointestinal parasites of cattle. Amphistomes were the second most important helminths identified. Strongyles are present in large numbers in domestic ruminants when compared to other parasites (Biu et al., 2009). Previously, Abraham et al., (2017) also identified strongyles as the most predominant cattle parasites followed by amphistomes in Wayanad.

Examination of fecal samples of buffaloes revealed ova of strongyles as the major parasitic ova.

In Rajasthan, examination of fecal samples of cattle and buffaloes revealed strongyle species with highest prevalence $(35.41 \%)$ followed by amphistomes (11.06\%) (Swarnakar et al., 2014). Moniezia spp. was the only cestode parasite infecting cattle encountered in the present study. According to Keyyu et al., (2006), the occurrence of cestode species is comparatively less in cattle. Higher incidence of intestinal parasitosis in cattle was during rainy season and least during summer. Marskole et al., (2016) also observed the high prevalence of parasitism during wet season. 
Table.1 Details of examination of clinical samples of ruminants

\begin{tabular}{|c|c|c|c|}
\hline \multicolumn{4}{|c|}{ FECAL SAMPLE EXAMINATION } \\
\hline Ova of Parasite & Cattle & Goat & Buffalo \\
\hline Strongyle & 146 & 185 & 8 \\
\hline Strongyloides spp. & 30 & 32 & 4 \\
\hline Oocysts of Eimeria & 80 & 74 & 5 \\
\hline Toxocara vitulorum & 23 & - & 1 \\
\hline Schistosoma spindale & 13 & - & - \\
\hline Amphistome & 118 & 7 & 1 \\
\hline Trichuris spp. & 33 & 27 & - \\
\hline Moniezia spp. & 7 & 37 & - \\
\hline Cryptosporidium spp. & 5 & - & - \\
\hline Total number of positive samples & 455 & 362 & 19 \\
\hline Total number of samples examined & 1304 & 505 & 49 \\
\hline \multicolumn{4}{|c|}{ BLOOD SMEAR EXAMINATION } \\
\hline Babesia bigemina & 74 & - & - \\
\hline Theileria spp. & 397 & 42 & 6 \\
\hline Anaplasma spp. & 56 & 36 & 1 \\
\hline Total number of positive samples & 527 & 78 & 7 \\
\hline Total number of samples examined & 1217 & 321 & 35 \\
\hline \multicolumn{4}{|c|}{ SKIN SCRAPING EXAMINATION } \\
\hline Psoroptes ovis & - & 3 & - \\
\hline Total number of positive samples & - & 3 & - \\
\hline Total number of samples examined & 17 & 13 & 1 \\
\hline \multicolumn{4}{|c|}{ EXAMINATION OF NASAL DISCHARGE } \\
\hline Schistosoma nasale & 3 & - & - \\
\hline Total number of samples examined & 12 & - & - \\
\hline
\end{tabular}


Table.2 Details of examination of clinical samples of non-ruminants and wild animals

\begin{tabular}{|c|c|c|c|c|c|c|}
\hline \multicolumn{7}{|c|}{ FECAL SAMPLE EXAMINATION } \\
\hline Ova of Parasite & Dog & Cat & Pig & Horse & Poultry & Wild animals \\
\hline Spirocerca lupi & 1 & - & - & - & - & - \\
\hline Ancylostoma spp./Strongyle & 35 & 1 & 1 & 13 & 6 & 12 \\
\hline Oocysts of Eimeria spp./ Isospora spp. & 1 & 1 & 3 & - & 24 & 1 \\
\hline Toxocara spp. & 14 & 5 & - & - & - & 12 \\
\hline Taenia spp. & 26 & - & - & - & - & 8 \\
\hline Dipylidium caninum & 1 & - & - & - & - & - \\
\hline Diphyllobothrium latum & 3 & - & - & - & - & - \\
\hline Trichuris spp. & - & - & - & - & - & 1 \\
\hline Paragonimus westermani & - & - & - & - & - & 24 \\
\hline Strongyloides spp. & - & - & - & - & - & 9 \\
\hline Spirometra spp. & - & - & - & - & - & 31 \\
\hline Balantidium coli & - & - & - & - & - & 1 \\
\hline Toxascaris leonina & - & - & - & - & - & 13 \\
\hline Capillaria spp. & - & 1 & - & - & 6 & - \\
\hline Ascaridia spp. & - & - & - & - & 10 & - \\
\hline Railletina spp. & - & - & - & - & 1 & - \\
\hline Total number of positive samples & 81 & 8 & 4 & 13 & 47 & 112 \\
\hline Total number of samples examined & 192 & 17 & 57 & 42 & 175 & 132 \\
\hline \multicolumn{7}{|c|}{ BLOOD SMEAR EXAMINATION } \\
\hline Trypanosoma evansi & 1 & - & - & - & - & 1 \\
\hline Haemogrigarine organism & - & - & - & - & - & 1 \\
\hline Theileria spp. & - & - & - & - & - & 1 \\
\hline Babesia spp. & 24 & - & - & - & - & 1 \\
\hline Hepatozoon spp. & 1 & - & - & - & - & - \\
\hline Ehrlichia spp. & 6 & - & - & - & - & - \\
\hline Haemoproteus columbae & - & - & - & - & 22 & - \\
\hline Microfilaria & 14 & - & - & - & - & - \\
\hline Total number of positive samples & 46 & - & - & - & 22 & 4 \\
\hline Total number of samples examined & 509 & 3 & 20 & 8 & 46 & 24 \\
\hline \multicolumn{7}{|c|}{ SKIN SCRAPING EXAMINATION } \\
\hline Sarcoptes spp. & 1 & - & 5 & - & - & - \\
\hline Demodex canis & 11 & - & - & - & - & - \\
\hline Total number of positive samples & 12 & - & 5 & - & - & - \\
\hline Total number of samples examined & 51 & 2 & 8 & - & - & - \\
\hline
\end{tabular}

Gastrointestinal parasites in goats are of significant importance as they cause heavy morbidity and mortality rates. In the present study, out of 505 fecal samples from goats examined, 362 were positive for intestinal parasitosis, indicating a high prevalence of
71.68 per cent. Overcrowding and mixed rearing of adults and kids can help in the transmission of endoparasites. These may be the causes for the increased incidence of endoparasitism among goats. Strongyles (36.63\%) were the predominant parasite. 
Haemonchus contortus is the important strongyle worm present in the abomasum of goats resulting in severe gastroenteritis, poor growth rate and even heavy mortality (Kagira and Kanyari, 2001; Singh et al., 2013). Coccidia (14.65\%) were the second most important protozoan parasite detected in goats. Coccidiosis causes abdominal pain, anemia, inappetance, diarrhoea, weakness and loss of weight (Soulsby, 1981). In addition, ova of Moniezia spp., Strongyloides spp., Trichuris spp. and amphistomes were also identified. Velusamy et al., (2015) also made similar observations in Tamil Nadu. The seasonal prevalence of intestinal parasitosis was highest in monsoon and lowest during winter seasons agreeing with previous reports (Velusamy et al., 2015; Pathak and Pal, 2008). Overcrowding, poor management and increased humidity during rainy season can predispose to increased incidences of parasitic infection. Low prevalence of intestinal parasitism in winter season was due to reduced grazing hours of the animals, which helped in reducing the chances of contact between host and parasites (Katoch et al., 2000).

Helminthosis is described as one of the major problems affecting health of dogs across the world (Traub et al., 2005). Coproexamination of dogs revealed highest incidence of ancylostomosis. Same observations were recorded by Vatsya et al., (2010) in Uttarakhand and Das et al., (2009) in Pudducherry. Hookworms were the most commonly identified parasite in dogs in Sikkim (71.3\%), Mumbai (48.8\%) and Delhi (39.1\%) (Traub et al., 2014). Cutaneous larva migrans (CLM) due to migration of canine hookworms under the skin of humans is a zoonotic infection. Even though occurrence of CLM in India is sporadic, dog owners are also exposed to the risk of eosinophilic enteritis, an emerging zoonotic infection due to $A$. caninum (Mc Carthy and Moore, 2000). A. ceylanicum, a hookworm of canids and felids in Asia, is becoming the second most common hookworm infecting humans (Inpankaew et al., 2012). Human cases due to A. ceylanicum have also been reported from Tamil Nadu, India (George et al., 2015). Thus, there is a need to emphasize on the control of zoonotic ancylostomosis. Taenia infection was the second most predominant helminthic infection followed by Toxocara canis in dogs. Toxocara canis is also having zoonotic significance causing visceral larva migrans in humans. Incidence of intestinal parasitosis was highest during rainy season and least during summer similar to previous reports of Vatsya et al., (2010).

Strongyle ova (30.95\%) were the only ova of gastrointestinal parasite of horses identified during examination of 42 fecal samples. Adeppa et al., (2016) also detected 44 samples positive for strongyle ova out of 100 fecal samples of horses in Karnataka.

Fecal examination of poultry showed higher incidence of oocysts of Eimeria spp. (13.71\%). Among the nematode infections, higher prevalence was for Ascaridia galli. Kumar et al., (2015) also observed similar findings. The only cestode ova identified was that of Railletina spp. No trematode ova were identified in this study.

Fecal samples of the wild felids like lions, tiger and leopard were examined. A total of 70 fecal samples of tigers were examined. Ova of Spirometra spp. and Paragonimus westermani were showing a prevalence of 44.29 and 34.29 per cent respectively. Paragonimus westermani is the most commonly encountered trematode parasite in both free-living and captive wild felids (Moudgil et al., 2015). Paragonimus westermani was encountered during necropsies of tigers from Corbett National Park in Uttar Pradesh (Arora and Das, 1988), 
Kanha National Park in Madhya Pradesh (Parihar and Shrivastava, 1988), Vandalur Zoological Park in Tamil Nadu (Latha et al., 2000) and Assam State Zoo in Guwahati (Nashiruddullah and Chakraborty, 2001). Ova of Toxascaris leonina was the major parasitic ova seen in lion. $T$. leonina is commonly found in dogs, cats and foxes; they are also seen in related wild species (Moudgil et al., 2015). Toxoascaris leonina infection in lion was also reported by Varadharajan and Kandasamy (2000) at Zoological Park, Coimbatore, Varadharajan et al., (2001) at Thrissur Zoo, Ravindran et al., (2006) at Ramgiri Estate, Wayanad. Toxocara spp. infection was identified in both lion and tiger. Toxocara spp. is also a zoonotic parasite which can cause visceral larva migrans.

Strongyle ova were the predominant parasitic ova in fecal samples of monkeys. Ova of Strongyloides spp. and Taenia spp. were also detected in monkeys. Varadharajan and Kandasamy (2000) also detected ova of strongyle and Strongyloides spp. in monkeys of Coimbatore.

Examination of cattle blood smears revealed $T$. orientalis as the highly prevalent blood parasite in cattle. Nair et al., (2011) observed thin rod and annular forms of $T$. orientalis in 61 out of 150 Giemsa's stained blood smears of apparently healthy cattle.

Theileria spp. and Anaplasma spp. were the blood parasites of goats identified in this study. Velusamy et al., (2015) also identified Theileria spp. and Anaplasma spp. as the blood parasites of small ruminants in Tamil Nadu.

Among dogs, B. gibsoni was the most prevalent blood parasite $(4.72 \%)$. Kumar et al., (2009) in Chennai also identified $B$. gibsoni as the major parasite with a prevalence of 9.83 per cent. Similar findings were observed by Battacharjee and Sarmah (2013) in North-east India. The incidence of microfilaria in Giemsa's stained peripheral blood smears of dogs in the present study was only 2.75 per cent, while prevalence rates of 7 per cent (Sabu et al., 2005) and 42.68 per cent (Ravindran et al., 2014) were also reported from Kerala. Majority of haemoparasitic diseases occurred during the month of November followed by April as previously reported by Kumar et al., (2009) in Chennai.

Haemoproteus columbae and its vector Pseudolynchia canariansis are widely distributed throughout the world especially in tropical and subtropical countries (Soulsby, 1981; Samani and Kheirabadi, 2013). In the present study, blood smear examination of pigeons revealed a high prevalence of 47.83 per cent for $H$. columbae. Hussein and Abdelrahim (2016) also reported a prevalence of 57.2 per cent for this parasite among pigeons of Egypt. The previously reported prevalence for $H$. columbae in adult pigeons was 60.93 per cent and young ones were 28.95 per cent from Kerala (Prasad et al., 2017). However, prevalence rates for $H$. columbae can vary from 6 to 86 per cent (Samani et al., 2013).

The common blood parasites observed in wild felids were T. evansi and Babesia spp. large cats, mainly tigers, are frequently infected with T. evansi (Acharjyo, 2000).

Demodex canis was identified as the major mite species infesting dogs of Northern Kerala with a prevalence rate of 21.57 per cent. Nayak et al., (1997) detected a prevalence rate of 3 per cent for demodicosis among dogs of Orissa. Psoroptes spp. $(23.08 \%)$ was the only mite species infesting goats identified in the present study. Chakrabarti (1994) and Parija et al., (1995) detected a prevalence of 13.4 per cent and 2.22 per cent for Psoroptes spp. among goats 
of Tripura and Bhubaneswar respectively. Microscopic examination of skin scrapings of pigs detected Sarcoptes scabiei var. suis mites. Laha et al., (2014) detected S. scabiei var. suis as the most prevalent mite species infesting pigs of Meghalaya. However, in the present study, less number of skin scrapings from different animals were examined.

Strongylosis was the predominant cause of gastrointestinal parasitosis in cattle, goat and dogs. Coccidiosis was one of the major parasitic infections in poultry. Gastrointestinal parasitism was more during the month of September in cattle and goats and July in dogs. Major blood parasites detected in ruminants (cattle, goat and buffalo) and dogs were $T$. orientalis and B. gibsoni respectively. Infections due to blood parasites were more during the month of January in cattle and November in dogs. Microscopical examination of skin scrapings from dogs detected maximum prevalence of Demodex canis in Northern Kerala.

\section{References}

Abraham, M., Harshal, P. T., Ajithkumar, K. G. and Ravindran, R. 2017. Coprological survey of gastrointestinal parasites of dairy cattle in Wayanad, Kerala, India. Int. J. Curr. Microbiol. App. Sci., 6(2): 899-903.

Acharjyo, L. N. 2000. Incidence of parasitic diseasees among wild mammals and their control in Indian zoos. Eleventh National Congress of Veterinary Parasitology, Bhubaneshwar, 4-6 February, 10-26pp.

Adeppa, J., Ananda, K. J., Krushnamurthy, C. M. and Satheesha, G. M. 2016. Incidence of gastrointestinal parasites in horses of Shimoga region, Karnataka state. J. Parasit. Dis., 40(3): 919-921.

ADSS (Animal Disease Surveillance Scheme), 2007. Department of Animal Husbandry, Kerala.

Allwin, B., Balakrishnan, S., Kumar, N.V., Jayathangaraj, M.G., Vedamanickam, S. and Gopal, S. 2016. Gaur (Bos gaurus) and domestic cattle at interface zones of the Nilgiri hills, Tamil Nadu, India. J. Vet. Sci. Technol., 7: 280.

Arora, B.M. and Das, S.C. 1988. Helminth infections in a tigress (Panthera tigris). Indian J. Vet. Med., 8: 154-156.

Bhattacharjee, K. and Sarmah, P.C. 2013. Prevalence of haemoparasites in pet, working and stray dogs of Assam and North-East India: A hospital based study. Vet. Wld, 6(11): 874-878.

Biu, A.A., Mamunatu, A., Salamatu, A.F. and Agbadu, E.T. 2009. A faecal survey of gastrointestinal parasites of ruminants on the University of Maiduguri research farm. Int. J. Biomed. Hlth. Sci., 5: 175-179.

Chakrabarti, A. 1994. Incidence of mange in goats in Tripura. Cheiron, 23: 122-126.

Das, S. S., Kumar, D., Sreekrishnan, R. and Ganesan, R. 2009. Gastrointestinal parasitic infections in dogs in Puducherry. J. Vet. Parasitol., 23(1): 77-79.

George, S., Kaliappan, S. P., Kattula, D., Roy, S., Geldhof, P., Kang, G., Vercruysse, J. and Levecke, B. 2015. Identification of Ancylostoma ceylanicum in children from a tribal community in Tamil $\mathrm{Nadu}$, India using a semi-nested PCR-RFLP tool. Trans. R. Soc. Trop. Med. Hyg., 109(4):283-285.

Hussein, N. M. and Abdelrahim, E. A. 2016. Haemoproteus columbae infection and its histopathological effects on pigeons in Qena Governorate, Egypt. IOSR J. Pharm. Biol. Sci., 11(1):79-90.

Inpankaew, T., Schär, F., Dalsgaard, A., Khieu, V., Chimnoi, W., Chhoun, C., Sok, D., Marti, H., Muth, S., Odermatt, P. and Traub, R. J. 2014. High prevalenc of Ancyclostoma ceylanicum hookworm infections in humans, Cambodia, 2012. Emerg. Infect. Dis., 20(6): 976-982.

Kagira, J. M. and Kanyari, P. W. N. 2001. The role of parasitic diseases in causing mortalities in small ruminants in a highly productive area of Central Province, Kenya. J. S. Afr. Vet. Assoc., 72:147-149.

Katoch, R., Chauhan, P. P. S. and Johri, D. K. 2000. Seasonal incidence of gastrointestinal nematodes in goats of Mathura region. Indian Vet. J., 77: 259-260.

Keyyu, J.D., Kassuku, A.A., Msalilwa, L.P., 
Monrad, J. and Kyvsgaard, N.C. 2006. Cross-sectional prevalence of helminth infections in cattle on traditional, smallscale and large-scale dairy farms in Iringa district, Tanzania. Trop. Anim. Hlth Prod., 30(1):45-55.

Kumar, K. S., Vairamuthu, S. and Kathiresan, D. 2009. Prevalence of haemoprotozoans in canines in chennai city. Cheiron, 5 (3): 104108.

Kumar, N., Rao, T. K. S., Varghese, A., Rathor, V.S. 2013. Internal parasite management in grazing livestock. J. Parasit. Dis., 37(2):151-157.

Kumar, S., Garg, R., Ram, H., Maurya, P. S. and Banerjee, P. S. 2015. Gastrointestinal parasitic infections in chickens of upper gangetic plains of India with special reference to poultry coccidiosis. J. Parasit. Dis., 39(1):22-26.

Laha, R., Das, M., Bharti, P. K., Kumar, S., Sen, A. and Goswami, A. 2014. Prevalence of Sarcoptes scabiei var. suis infestation in pigs of Meghalaya and its treatment. Vet. Wld., 7: 1137-1139.

Latha, B.R., Ramesh, S., Janathangaraj, M.G.and Methew, C.J. 2000. Concurrent Paragonimus and Spirometra infection in a tigress. Indian J. Vet. Med., 20: 96.

Marskole, P., Verma, Y., Dixit, A. K. and Swamy, M. 2016. Prevalence and burden of gastrointestinal parasites in cattle and buffaloes in Jabalpur, India. Vet. Wld., 9(11): 1214-1217.

McCarthy, J. and Moore, T. A. 2000. Emerging helminthes zoonoses. Int. J. Parasitol., 30:1351-1360.

Moudgil, A.D., Singla, L.D. and Pallavi. 2015. Parasitosis in wild felids of India: an overview. J. Threat. Taxa., 7(10): 76417648.

Nair, A.S., Ravindran, R., Lakshmanan, B., Kumar, S.S., Tresamol, P.V., Saseendranath, M.R.,Senthilvel, K., Rao, J.R., Tewari, A.K. and Ghosh, S. 2011. Haemoprotozoa of cattle in Northern Kerala, India. Trop. Biomed., 28(1): 68-75.

Nashiruddullah, N. and Chakraborty, A. 2001. Parasites of captive wild carnivores of Assam State Zoo. Intas-Polivet, 2: 173-181. Nayak, D.C., Tripathy, S.B., Dey, P.C., Ray, S.K.,
Mohanty, D.N., Parida, G.S., Biswal, S. and Das, M. 1997. Prevalence of canine demodicosis in Orissa (India). Vet. Parasitol., 73(3-4): 347-352.

Parihar, N.S. and Shrivastava S.N. 1988. Bronchial hyperplasia in a tiger (Panthera tigris). Indian J. Anim. Sci., 58: 230-233.

Parija, B.G., Misra, S.C. and Sahoo, P.K. 1995. Changing pattern in the epidemiology of caprine mange in Bhubaneswar. Indian Vet. $J ., 72:$ : 536-538.

Pathak, A. K. and Pal, S. 2008. Seasonal prevalence of gastrointestinal parasites in goats from Durg district of Chhattisgarh. Vet. Wld., 1(5):136-137.

Prasad, K., Barman, D., Asif, M. M. and Abraham, J. 2017. Pigeon farming practices and constraints in Kerala. Glob. J. Biosci. Biotechnol., 6 (1): 86-88.

Quinquennial livestock census, 2012. Ministry of agriculture, Department of animal husbandry, dairying and fisheries, New Delhi, India. 130p.

Ravindran, R., Lakshmanan, B., Anoop, S., Rajeev, T.S. and Dinesh, C.N. 2006. Parasitic infection in captive lions (Panthera leo) at Wayanad. Zoos Print J., 21(4): 2230.

Ravindran, R., Varghese, S., Nair, S. N., Balan,V. M., Lakshmananan, B., Ashruf, R. M., Kumar, S. S., Gopalan, A. K.K., Nair, A. S., Malayil, A., Chandrashekar, L., Juliet, S., Devada, K., Ramachandran, R., Kunjupillai, R. and Kakada, S. A. M. 2014. Canine filarial infections in a human Brugia malayi endemic area of India. BioMed Res. Int., http://dx.doi.org/10.1155/2014/630160.

Sabu, L. Devada, K. and Subramanian, H. 2005. Dirofilariosis in dogs and humans in Kerala. Indian J. Med. Res., 121: 691-693.

Samani, A. D. and Kheirabadi, K. P. 2013. Prevalence and rate of parasitemia of Haemoproteus columbae in Columba livia domestica in Southwest of Iran. Iranian J. Parasitol., 8(4): 641-644.

Singh, V., Varshney, P., Dash, S. K. and Lal, H. P. 2013. Prevalence of gastrointestinal parasites in sheep and goats in and around Mathura, India. Vet. Wld., 6(5):260-262.

Soulsby, E. J. L. 1981. Helminths, arthropods and protozoa of domesticated animals. Bailliere 
and Tindall, London, 291-294.

Swapna.S. and Nithinya, R. 2015. Prevalence of gastrointestinal nematode and trematode parasites of cattle in northern Kerala, India. Int. J. Sci. Eng., 3(2): 132-136.

Swarnakar, G., Kumawat, A., Sanger, B., Roat, K. and Goswami, H. 2014. Prevalence of amphistome parasites (Trematoda: Digenea) in Udaipur of Southern Rajasthan, India. Int. J. Curr. Microbiol. App. Sci., 4: 32-37.

Traub, R. J., Pednekar, R. P., Cuttell, L., Porter, R. B., Rani, P. A. A. M. and Gatne, M. L.2014. The prevalence and distribution of gastrointestinal parasites of stray and refuge dogs in four locations in India. Vet. Parasitol., $205:$ :233-238.

Traub, R. J., Robertson, I. D., Irwin, P. J., Mencke, N. and Thompson, R. C. A. A. 2005. Canine gastrointestinal parasitic zoonoses in India. Trends Parasitol., 21: 42-48.

Vanisri, V., Subramanian, N. and Muthu, M. 2016. Prevalence of gastrointestinal parasites in cattle in and around cheyyar Taluk, Thiruvannamalai district. Int. J. Inf. Res. Rev., 3(11): 3282-3294.
Varadharajan, A. and Kandasamy, A. 2000. A survey of gastrointestinal parasites of wild animals in captivity in the V.O.C. park and mini zoo, Coimbatore. Zoos Print J., 15(5): 257-258.

Varadharajan, A., Pythal, C. and Subramanian H. 2001. Investigation on the prevalence of helminth parasites of wild mammals in the Thrissur Zoo, Kerala. Cheiron, 30: 12-15.

Vatsya, S., Garg, R., Kumar, R. R., Yadav, C. L. and Banerjee, P. S. 2010. Retrospective study on the incidence of gastrointestinal and blood parasites in dogs at Pantnagar and their public health significance. J. Vet. Pub. Hlth., 8(1): 29-32.

Velusamy, R., Rani, N., Ponnudurai, G. and Anbarasi, P. 2015. Prevalence of intestinal and haemoprotozoan parasites of small ruminants in Tamil Nadu, India. Vet. Wld., 8(10): 1205-1209.

Velusamy, R., Rani, N., Ponnudurai, G., Harikrishnan, T. J., Anna, T., Arunachalam, K., Senthilvel, K. and Anbarasi, P. 2014. Influence of season, age and breed on prevalence of haemoprotozoan diseases in cattle of Tamil Nadu, India. Vet. Wld, 7(8): 574-578.

\section{How to cite this article:}

Murikoli Nimisha, R. Kariyappa Pradeep, Prashant S. Kurbet, B.M. Amrutha, Anju Varghese, C.K. Deepa, M.N. Priya, Bindu Lakshmanan, K.G. Ajith Kumar and Reghu Ravindran. 2017. Parasitic Diseases of Domestic and Wild Animals in Northern Kerala: A Retrospective Study based on Clinical Samples. Int.J.Curr.Microbiol.App.Sci. 6(11): 2381-2392. doi: https://doi.org/10.20546/ijcmas.2017.611.282 